This item was submitted to Loughborough's Research Repository by the author.

Items in Figshare are protected by copyright, with all rights reserved, unless otherwise indicated.

\title{
Effect of nozzle geometry on air-jet texturing performance
}

PLEASE CITE THE PUBLISHED VERSION

http://dx.doi.org/10.1177/004051759606600204

\section{PUBLISHER}

Sage (๑) Textile Research Institute)

\section{VERSION}

AM (Accepted Manuscript)

\section{PUBLISHER STATEMENT}

This work is made available according to the conditions of the Creative Commons Attribution-NonCommercialNoDerivatives 4.0 International (CC BY-NC-ND 4.0) licence. Full details of this licence are available at: https://creativecommons.org/licenses/by-nc-nd/4.0/

\section{LICENCE}

CC BY-NC-ND 4.0

\section{REPOSITORY RECORD}

Bilgin, Sule, Hendrik K. Versteeg, and Memis Acar. 2019. "Effect of Nozzle Geometry on Air-jet Texturing Performance". figshare. https://hdl.handle.net/2134/22040. 


\title{
Effect of Nozzle Geometry on Air-Jet Texturing Performance
}

\author{
S. BILGIN \\ Uludag Universitesi, Muhendislik-Mimarlik Fakultesi, Tekstil Muhendisligi Bolumu, \\ Gorukle 16059, Bursa, Turkey \\ H.K.VERSTEEG AND M.ACAR \\ Department of Mechanical Engineering, Loughborough UniversityofTechnology, \\ Loughborough: Leicestershire, LE 113 TU, United Kingdom
}

\begin{abstract}
This paper systematicallyinvestigates theeffect of a number of geometric parameters on the texturing performance of air-jet texturing nozzles. In order to facilitate the research, an air-jet texturing nozzle with a rectangular cross section has been developed. The texturing performance of the nozzles is assessed by means of process observations and on-line measurement of stabilizing zone tension, and also by measuring the increased linear density of the yarns on textured yarn samples. Furthermore, instability, elongation at break, and tenacity are measured, and texturing quality is judged by visual inspections and examination of scanning electron microscopy images of the textured yams. Tension in the stabilizing zone, increase in linear density, and to a somewhat lesser extent instability are reliable measures of texturing quality. The best texturing comes from nozzles with a slightly diverging main channel and a single air inlet hole located far from the nozzle exit. A curved diverging exit profile is essential for successful texturing. The results of the tests to determine the effect of air inletangle are inconclusive and require further investigation.
\end{abstract}

The air-jet texturing process is widely known for its ability to produce spun-like synthetic continuous filament yarns. Structural modification is achieved by contact of the continuous feed yarn with a supersonic air stream delivered by a nozzle. The details of the flow patterns are influenced by the geometry of the nozzle. This relationship between nozzle shape and air flows has been investigated in detail by Acar et al. [1] and Demir et al. [5]. Acar et al. [4] also studied the air flow in texturing nozzles theoretically and developed a mathematical model of the flow through cylindrical nozzles. The behavior of filaments during texturing and the fluid forces acting on the filaments are discussed further in Acar et al. [2, 3]. An overview of this re-search, also found in Wray and Acar [IO], concludes that the air flow is invariably supersonic and highly turbulent and that the velocity distribution of the emerging jet is usually asymmetric. Details of the process depend on the geometry of 
the nozzle and also on the properties of the filaments constituting the yarn (feed material, linear density, filament cross-sectional shape, etc.).

In spite of the advanced state of the research, its findings have, to date, not yet succeeded in relating the properties of air-jet textured yarns to nozzle geometry. A companion paper, Versteeg et al. [8], reports a preliminary investigation of the effect of nozzle geometry on air flow properties and texturing quality for a range of cylindrical industrial nozzles. However, since the geometry did not vary in a systematic way for industrial nozzles, it was not possible to establish which geometric parameter or combination of parameters was responsible for changes in yarn properties. In our study, we investigate a series of systematically designed experimental rectangular texturing nozzles and establish the influence of nozzle shape on texturing performance.

\section{Rectangular Nozzle Design}

Some of the most widely used air-jet texturing nozzles in industry are of the Heberlein HemaJet type, whose basic design consists of a uniform main channel of circular cross section with a trumpet-shaped exit section and an air inlet passage at an angle of approximately $45^{\circ}$ to introduce the compressed air. The main channel of the HemaJet nozzles is typically between 1.5 and $2.5 \mathrm{~mm}$ diameter, and has a length of approximately $30 \mathrm{~mm}$ and a very smooth surface finish. The ratio of air inlet to main channel cross-sectional area of such nozzles varies between 0.5 and 0.75 . Production of the long and slender circular holes, which form the main channel in HemaJet nozzles, is a complex and expensive operation.

In order to make the systematic study of geometry effects possible, we designed a series of nozzles with rectangular main channel cross sections. Early tests with a prototype design revealed that yarns textured by such nozzles have properties and a quality similar to those of yarns produced by industrial nozzles. We kept the geometry of the experimental rectangular nozzles as similar to cylindrical industrial nozzles as possible. We selected one of the more commonly used and successful commercial nozzles, the Heberlein T100, as the basis of the design.
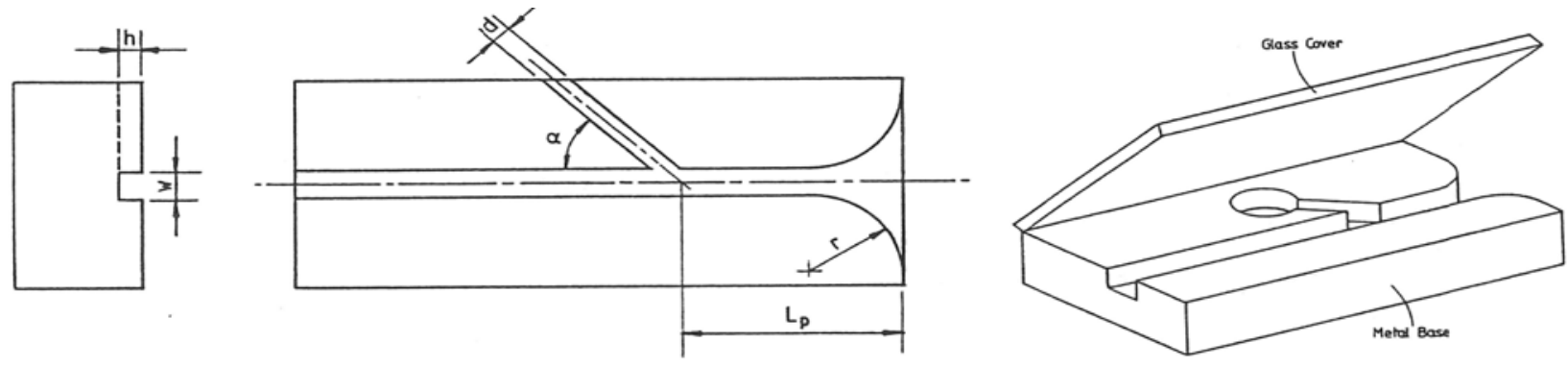

FIGURE 1.Nozzle geometry and isometric view.

In the rectangular nozzles, the compressed air is de- livered through a rectangular inlet hole at an angle of $a=45$ degrees to the rectangular main duct. The nozzle exit is a smoothly curved diverging profile with the shape of a quarter circle with a radius of $r=6 \mathrm{~mm}$. Figure 1 shows details of the geometry of the experimental nozzles by 
means of cross-sectional and isometric views. In this study, the depth and width of the main channel were kept constant at $h=1.0$ and $w=1.5 \mathrm{~mm}$, respectively. The depth and width of the rectangular air inlet channel were also both kept constant at $1.0 \mathrm{~mm}$, leading to a ratio of air inlet to main channel cross-sectional area of 2:3. Further rectangular nozzles were systematically derived from the base de- sign by varying one single geometric parameter at a time.

Table I defines the geometric parameters of the nozzles. The following is a summary of the nozzle geometry: Nozzles 1-9 have nine different values of primary flow length LP, i.e., the distance between air inlet and nozzle exit, ranging from 4 to $16 \mathrm{~mm}$. The reference nozzle is nozzle 5 with a value of $L P$ of $10 \mathrm{~mm}$. Nozzles I 0 and 11 have two different angles $a$ of the air inlet hole to the main channel, $30^{\circ}$ and $60^{\circ}$. The inlet angle $a$ of nozzle 5 is $45^{\circ}$. Nozzle 12 has a rectangular exit profile. This nozzle has a sharp $90^{\circ}$ exit; reference nozzle 5 has a curved exit profile. Nozzle 13 has two inlet holes on opposite sides of the main channel. Nozzle 5 has one air inlet. Nozzle 14 has a diverging main channel between the air inlet hole and the nozzle exit; the half angle of divergence $\beta$ is $1^{0}$. The main channel of nozzle 5 is straight.

TABLE I. Design geometry of the experimental rectangular texturing nozzles.

\begin{tabular}{llllll}
\hline $\begin{array}{l}\text { Nozzle } \\
\text { number }\end{array}$ & $\begin{array}{l}\text { Primary flow } \\
\text { length } L, \mathrm{~mm}\end{array}$ & $\begin{array}{l}\text { Air inlet } \\
\text { angle } a, \\
\text { degrees }\end{array}$ & $\begin{array}{l}\text { Divergence } \\
\text { angle, } \\
\text { degrees }\end{array}$ & $\begin{array}{l}\text { Curved exit } \\
\text { profile }\end{array}$ & $\begin{array}{l}\text { Number of } \\
\text { air inlets }\end{array}$ \\
\hline 1 & 4.0 & 45 & 0 & yes & 1 \\
2 & 5.5 & 45 & 0 & yes & 1 \\
3 & 7.0 & 45 & 0 & yes & 1 \\
4 & 8.5 & 45 & 0 & yes & 1 \\
5 & 10.0 & 45 & 0 & yes & 1 \\
6 & 11.5 & 45 & 0 & yes & 1 \\
7 & 13.0 & 45 & 0 & yes & 1 \\
8 & 14.5 & 45 & 0 & yes & 1 \\
9 & 16.0 & 45 & 0 & yes & 1 \\
10 & 6.3 & 30 & 0 & yes & 1 \\
11 & 12.1 & 60 & 0 & yes & 1 \\
12 & 10.0 & 45 & 0 & no & 1 \\
13 & 10.0 & 45 & 0 & yes & 2 \\
14 & 10.0 & 45 & 1 & yes & 1 \\
\hline
\end{tabular}

To simplify the manufacturing process, the nozzles were designed in two parts. The main channel, air inlet slot, and exit profile were machined in the first part of the nozzle (base). The second part (cover) was a simple flat plate secured to the first part to form a closed nozzle. In these tests, the base was made from brass, but-industrial nozzles of this novel design should be produced out of much more wear-resistant material. The cover would normally be fabricated out of the same material as the base, but for the purposes of process visualization, we used a glass plate. 


\section{Processing Conditions of Texturing Trials and Yam Quality Assessment}

In all trials, the supply yarn was PET 176/66 and the processing conditions, which are typical of industrial air-jet texturing, included 8 bar (gauge) air supply pressure, $200 \mathrm{~m} / \mathrm{min}$ yarn speed, $20 \%$ overfeed, $4 \%$ stabilizing draw ratio, and 1 liter/hour water.

We assessed the texturing performance of the rectangular nozzles by means of the following measurements and observations: process observations, measurement of tension in the stabilizing zone, yarn tests (increased linear density, instability, tenacity, and elongation at break), yarn quality assessment by visual inspection and scanning electron microscopy (SEM) photographs.

Specimens of yarns used for tensile testing were not wound on bobbins to avoid permanent damage to the yarn due to high and fluctuating tension caused by the winding-up process. Specimens for the linear density increase measurements were collected by keeping the wind-up tensions at around 15 to $20 \mathrm{cN}$; these values are typical of the stabilizing zone tensions measured during processing.

Details of the tensile test procedures and the stabilizing zone tension measurement are presented in Versteeg et al. [8]; for the sake of brevity, they are not repeated here, but the concept of instability deserves a brief explanation.Loops that characterize air-jet textured yarns can be irrecoverably pulled out by applying tension. Such permanent extension of the yarn under working tensions in Subsequent fabric forming processes would be disadvantageous, since the bulk of the yarn is reduced. The instability of air-jet textured yarns can be defined as a measure of the tendency of the yam to elongate under applied loads, thereby corresponding to the loads applied during weaving or knitting, etc. A variation of this concept is also used in measuring yarn instability where the elastic (recoverable) deformation of the yarn under the applied loads does not contribute, and only permanent elongation is measured after load removal.

Since air-jet textured yarns are maintained under tension during most of the further fabric forming processes, it would be more reasonable to take the elongation of the yarn under a maintained tension as a measure of yarn instability. Hence, we measured the instability of the air-jet textured yarns as a percentage elongation by applying an initial load of $0.01 \mathrm{cN} / \mathrm{dtex}$, based on the initial linear density of the yarn, for a single end yarn specimen, and then increasing this load to $0.5 \mathrm{cN} /$ dtex. This is best achieved by using a tensile test machine and procedures outlined by Demir et al. [6].

\section{Results}

The results of all the measurements for the rectangular nozzles are presented in Table II, together with those of the cylindrical industrial nozzle Heberlein T100, whose dimensions served as a basis for the design of reference nozzle 5 .

Estimated errors for the measured values are quantified as follows: Stabilizing zone tension was measured on-line during texturing. Some low frequency fluctuations were experienced even in the course of stable texturing, but a meaningful average was easily recorded over an interval of 30 to 60 seconds. The measurements were very repeatable, and our overall assessment of the absolute error in the normalized 
stabilizing tensions reported in Table II is \pm 0.03 . The standard deviations of the tensile test results are quoted in brackets in Table II. Finally, increased linear density was measured on one $50 \mathrm{~m}$ sample of each textured yarn, using standard techniques. Previous work [8] has shown that this procedure has good repeatability, and we estimate from this work that the expected absolute error in the present data is $\pm 0.1 \%$.

Most test results for yarns produced by Tl00 fall within the range of those of the rectangular nozzles, indicating that the yarns from the experimental nozzles have properties similar to those of industrial nozzles.

TABLE II. Properties of textured yams produced by the experimental nozzles.

\begin{tabular}{llllll}
\hline $\begin{array}{l}\text { Nozzle } \\
\text { number }\end{array}$ & $\begin{array}{l}\text { Normalized tension } \\
\text { stabilizing zone }\end{array}$ & $\begin{array}{l}\text { Increase in linear } \\
\text { density, } \%\end{array}$ & $\begin{array}{l}\text { Instability, } \\
\%\end{array}$ & $\begin{array}{l}\text { Elongation at } \\
\text { break, } \%\end{array}$ & $\begin{array}{l}\text { Tenacity, } \\
\text { cN/dtex }\end{array}$ \\
\hline T100 & 1.00 & 11.2 & $2.9 \pm 0.09$ & $14.1 \pm 1.1$ & $2.07 \pm 0.09$ \\
2 & 0.82 & 8.9 & $3.0 \pm 0.20$ & $19.8 \pm 1.0$ & $2.38 \pm 0.05$ \\
3 & 0.47 & 5.9 & $5.5 \pm 0.35$ & $20.3 \pm 4.0$ & $2.27 \pm 0.35$ \\
4 & 0.65 & 8.2 & $3.7 \pm 0.20$ & $19.9 \pm 1.3$ & $2.38 \pm 0.06$ \\
5 & 0.82 & 9.3 & $3.4 \pm 0.21$ & $18.0 \pm 2.0$ & $2.28 \pm 0.17$ \\
6 & 0.79 & 8.8 & $3.1 \pm 0.10$ & $17.2 \pm 1.7$ & $2.23 \pm 0.14$ \\
7 & 0.79 & 9.8 & $3.0 \pm 0.20$ & $15.3 \pm 1.2$ & $2.14 \pm 0.06$ \\
8 & 0.97 & 10.8 & $3.0 \pm 0.06$ & $16.5 \pm 1.4$ & $2.22 \pm 0.13$ \\
9 & 1.03 & 11.5 & $2.7 \pm 0.17$ & $15.1 \pm 2.1$ & $2.14 \pm 0.17$ \\
10 & 0.79 & 9.8 & $2.9 \pm 0.13$ & $14.8 \pm 1.0$ & $2.12 \pm 0.09$ \\
11 & 0.59 & 8.3 & $3.2 \pm 0.19$ & $16.9 \pm 1.3$ & $2 . \mathrm{L} 8 \pm 0.10$ \\
13 & 0.68 & 9.0 & $3.0 \pm 0.29$ & $16.2 \pm 1.1$ & $2.30 \pm 0.10$ \\
14 & 1.15 & 11.3 & $2.4 \pm 0.05$ & $13.8 \pm 1.2$ & $2.14 \pm 0.11$ \\
\hline
\end{tabular}

\section{PROCESS OBSERVATIONS}

There are no data in Table II for nozzles 1 and 12, since their geometries did not produce stable texturing conditions. Nozzle 1 has an air inlet hole positioned at the curved nozzle exit. The jet emerges from the air inlet at an angle of $45^{\circ}$ to the yarn path and leaves the nozzle without impacting on the main channel cross section. The texturing process created by nozzle 12 pulsed the yarn at irregular intervals, causing unstable processing conditions. Sometimes it was possible to produce yams, but on other occasions, under notionally identical process conditions, texturing did not take place. All other nozzles gave stable texturing under the processing conditions described earlier.

\section{STABILIZING ZONE TENSION MEASUREMENTS}

The tension measurements in the stabilizing zone reported in Table II are given as normalized values with respect to the tension measured for nozzle T100 $(17.55 \mathrm{cN})$ to indicate the comparative nature of the measurement. Stabilizing zone tension is a good measure of texturing effectiveness, since it detects the extent to which loops 
formed by the texturing process are actually entangled and anchored in the core of the yarn. Figure 2 illustrates the relationship between stabilizing tension and the primary flow length $L P$. Whereas nozzle 1 , with an extremely short primary flow length of $4 \mathrm{~mm}$, did not give stable texturing, there appears to be a nonstandard texturing regime associated with nozzle 2 , whose primary flow length $(5.5 \mathrm{~mm})$ approximately equals the exit radius $(6 \mathrm{~mm})$. This peculiar regime gives intermediate values of stabilizing zone tension. Thereafter, the general trend shows a gradual increase in stabilizing tension as $L P$ increases. The highest stabilizing tensions, which indicate the most favorable texturing conditions, are obtained with the long primary flow lengths. Later we will discuss the fundamental causes of this behavior in more detail. Table II also shows that the nozzles with low inlet angles $\left(30^{\circ}\right.$ and $\left.45^{\circ}\right)$ and the one with a diverging main channel produce high tension in the stabilizing zone. The nozzle with two inlets generates low stabilizing tension.

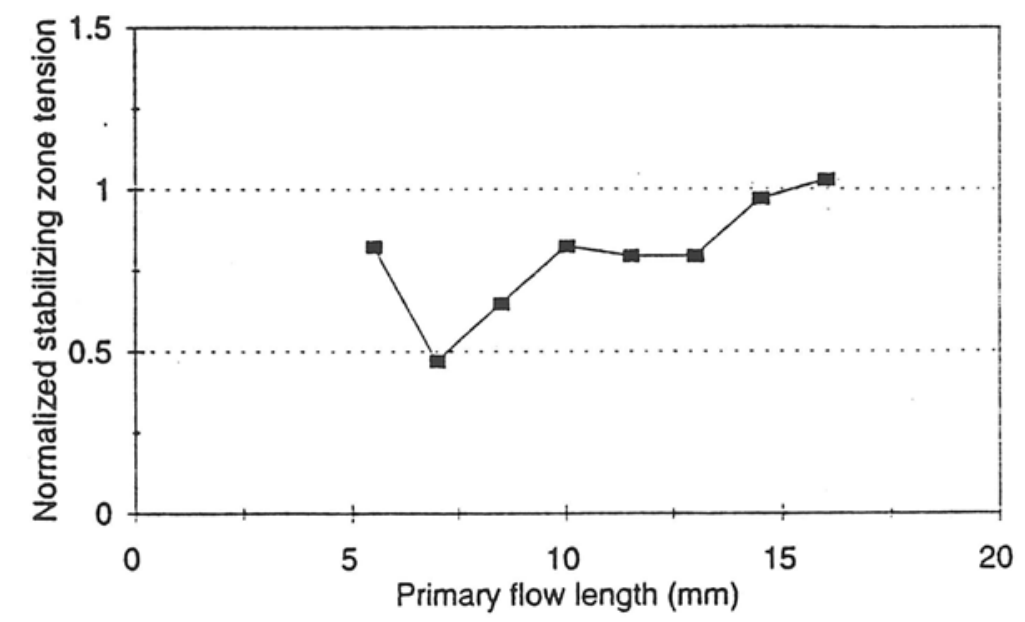

FIGURE 2. Relationship between normalized stabilizing tension and primary flow length for nozzles 2-9.

\section{INCREASED LINEAR DENSITY}

The increase in linear density after texturing indicates the degree of take-up of the overfeed and, provided reasonable care is taken to avoid damage to the yarn structure during winding up, it is a good measure of the overall efficiency of loop formation during texturing.

The trends of increased linear density are very similar to those for the stabilizing zone tension. In Figure 3, data for nozzles 2 to 9, which have increasing primary flow length $L P$, show a general increase with increasing primary flow length, with the exception of nozzle 2, which gives a medium value of linear density increase. A comparison of the data for nozzle 5 with those for nozzles 10 to 14 in Table II illustrates the other geometry effects. These show that in order to achieve a high increase in linear density, it is advantageous to have a long main channel length, a low inlet angle $\left(45^{\circ}\right.$ or less), and a diverging passage. 


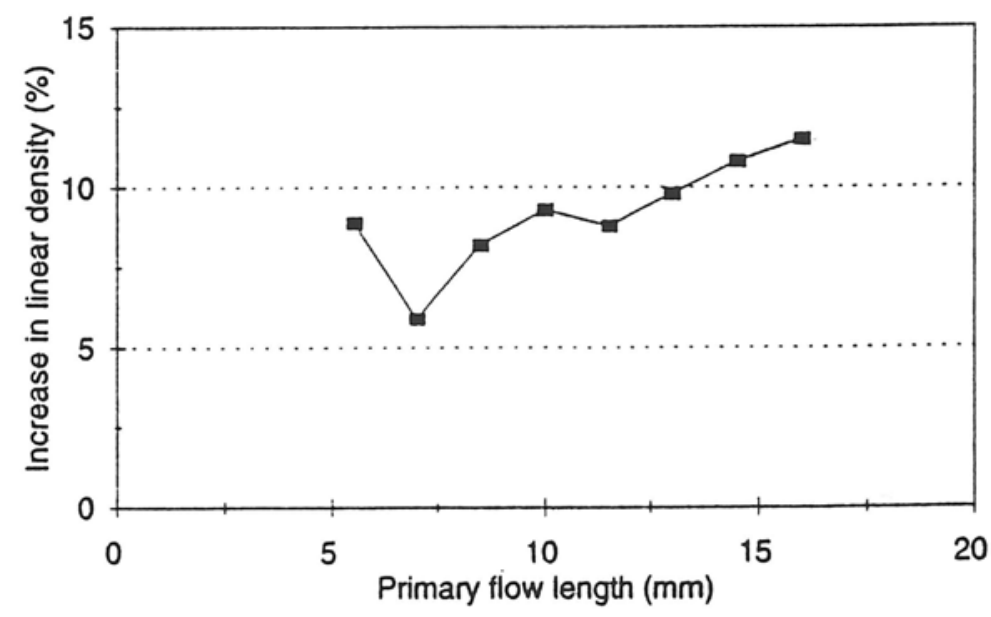

FIGURE 3. Relationship between increase in linear density and primary flow length for nozzles 2-9.

\section{TENSILE TESTS}

The results of the tensile tests on the textured yarns provide useful information about the strength and elasticity of the yarn, but are not very effective indi-cators of texturing quality. The results in Figures 4 and 5 show that the trends in instability and elongation at the more subtle differences in structure between the break correlate to a limited extent with the other two objective measures of texturing: high instability values and high elongation at break are generally associated with low stabilizing zone tensions and low linear density increase, whereas low instabilities and elongations at break correspond to high stabilizing zone tensions and increased linear density.

Within the variability of the test data given in Table II, tenacity is substantially unaffected by texturing within the range of geometries investigated here. Figure 5 shows that the elongation at break is somewhat higher for those yarns produced by nozzles with short primary flow length.

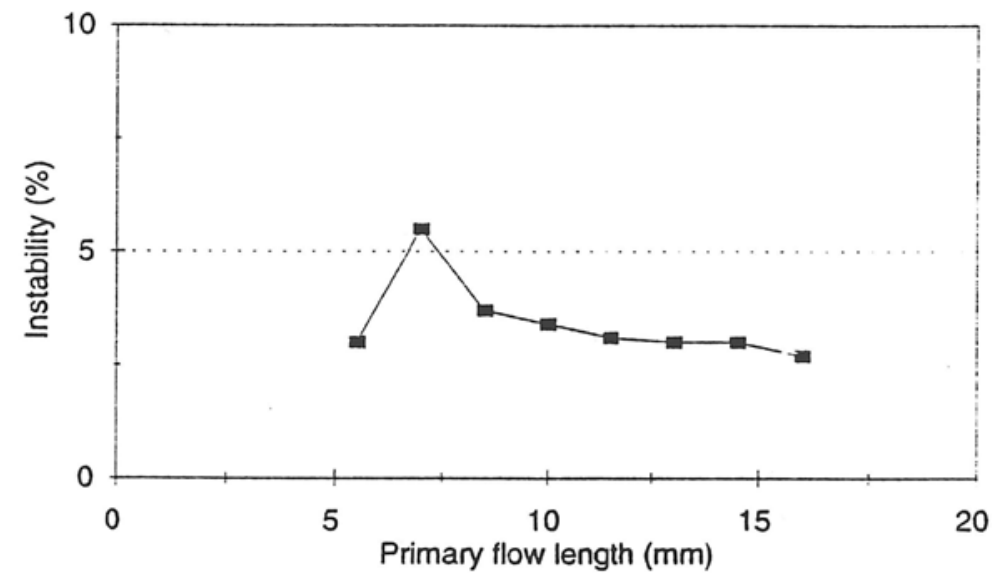

FIGURE 4. Relationship between yam instability and primary flow length, nozzles 2-9. 


\section{VISUAL INSPECTION AND SEM YARN IMAGES}

Visual inspection allows an overall appraisal of the textured yarns, and SEM images powerfully illustrate the more subtle differences in structure between the various yarns. Both visual inspection and SEM images provide qualitative information about the degree of yarn texturing. Here we examine the SEM images of textured yarn samples given in Figures $6 a$ and $6 b$.

Both sets of photographs compare the texturing quality of the experimental rectangular nozzles with industrial nozzle HemaJet TIOO. Features that are distinctive of well-textured yarns are large numbers of small loops that are well anchored in a tightly closed core. The SEM images of yarns produced by T 100 and nozzles 7, 8, 9, and 14 are characteristic of such good quality yarn. Poorly textured yarns show intermittent texturing or large open sections and wide loops in con- junction with a loose core structure. Yarns produced by nozzles 3, 4, and 11 are examples of poor texturing.

In order to highlight the effect of primary flow length $L P$ on yarn quality, the SEM images for the series of nozzles 2 to 9 corresponding to nozzles with values of $L P$ ranging from 5.5 to $16 \mathrm{~mm}$ are presented in Figure 6a. There is a clear trend towards more effective texturing as the primary flow length-of the nozzle in- creases. This trend corresponds to those found for stabilizing zone tension, increase in linear density, and instability. The quality of the most effectively textured yarns also compares favorably with the yarn produced by HemaJet TI00.

Figure $6 \mathrm{~b}$ shows SEM images of yarns produced by the remaining nozzles; the image of yarn produced by T 100 is repeated for comparative purposes. The top three images compare the effect of inlet angles of $30^{\circ}, 45^{\circ}$, and $60^{\circ}$, respectively, and the images that follow show yarns produced by nozzle 13 , which has two inlet holes, and by nozzle 14 , which has a slightly diverging main channel. The differences in the quality of texturing between yarns produced by these rectangular nozzles are slight, but the indications are that the yarn produced by nozzle 11 with an inlet angle of $60^{\circ}$ is not as well textured as those with inlet angles of $30^{\circ}$ and $45^{\circ}$. The double inlet does not improve texturing quality, but the diverging main channel gives a tight core with small loops and is clearly beneficial for texturing.

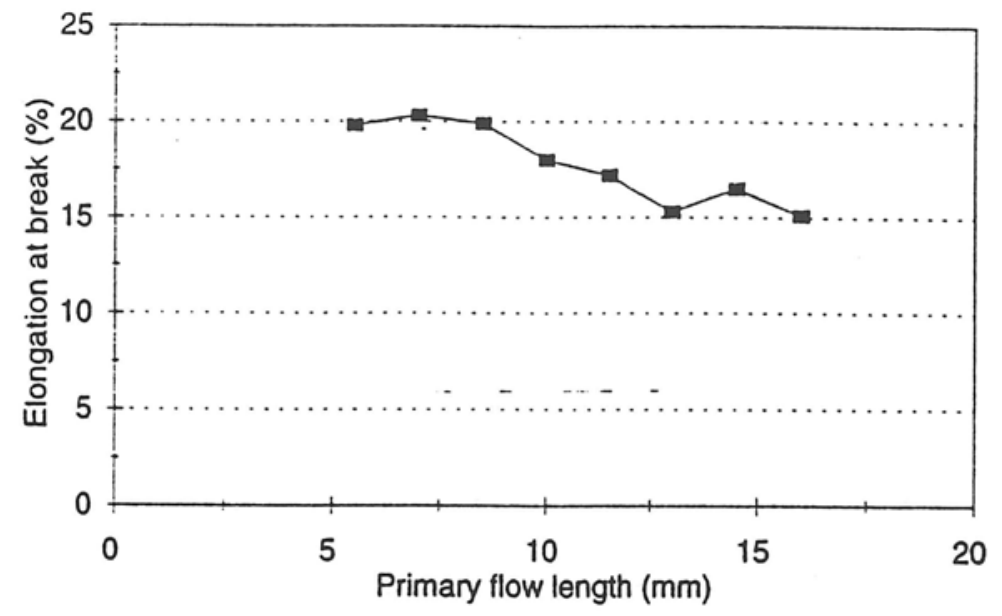

FIGURE 5. Relationship between elongation at break and primary flow length for nozzles 2-9. 

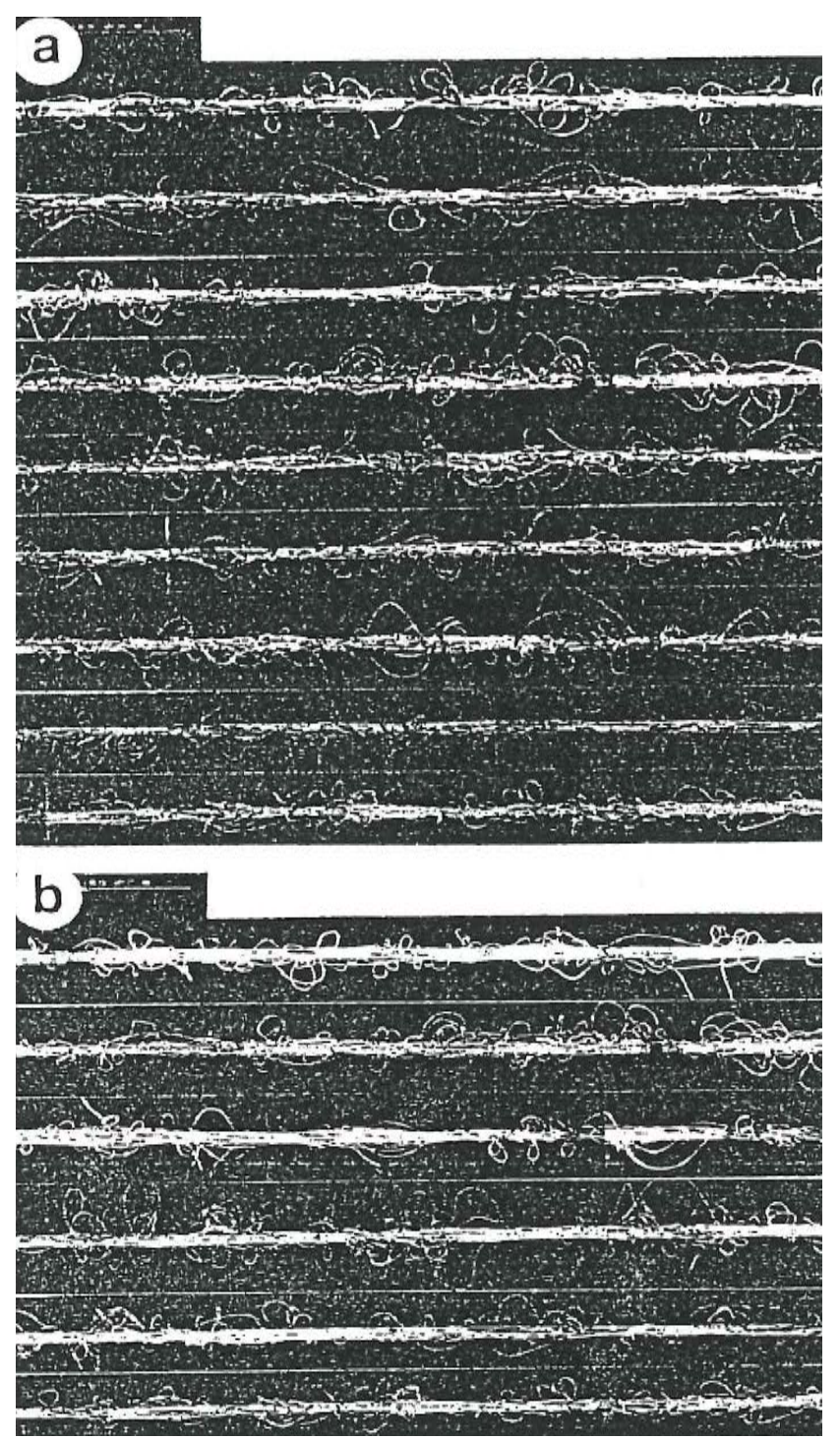

FIGURE 6. Scanning electron microscopy images of yarns produced by (a) nozzles 2-9 and TI00 (top to bottom), and (b) nozzles 10- 12 (30 $40^{\circ}, 60^{\circ}$ inlet angles), nozzle 13 (double inlet), nozzle 14 (diverging inlet), and TIOO (top to bottom).

\section{Discussion and Conclusions}

\section{QUANTITATIVE MEASURES OF TEXTURING QUALITY}

The results of the qualitative assessment of the SEM images correlate well with those obtained for the quantitative measures of tension in the stabilizing zone, in- crease in linear density, and instability. Where the tension in the stabilizing zone and increased linear density are high and where instability is low, the SEM images generally show yarns with a tight core and well entangled loops. Conversely, in cases where there is a low tension in the stabilizing zone and a low increase in linear density along with high instability, the SEM images show poorly textured yam.

There is also an encouraging degree of correlation between the three main quantitative measurements. This is illustrated in Figures $7 \mathrm{a}$ and $7 \mathrm{~b}$, where the tension in the stabilizing zone is plotted against the in- crease in linear density and the 
instability. The strong positive correlation between increased linear density and stabilizing zone tension can be attributed to an effective texturing process that ensures good loop formation followed by successful anchoring of these loops within the final yam structure. The correlation between stabilizing zone tension and instability is weaker, particularly for the better textured yams for which the stabilizing tension is high. This is due to the fact that the tension associated with instability measurements is not always close in magnitude to the stabilizing zone tension. In fact, in many cases, the final tension during an instability test may be an order of magnitude higher.

Consequently, the entangled structure of textured yam is almost always entirely destroyed at tensions pre-vailing during an instability measurement. Thus, the value of the instability is only partly associated with the degree of entanglement of the textured yarn.

In summary, we conclude that the stabilizing zone tension, increased linear density and, to a somewhat lesser extent, instability emerge as the more reliable indicators of effectiveness of the air-jet texturing process. Tenacity and elongation at break of the yarns are poor indicators of texturing quality.
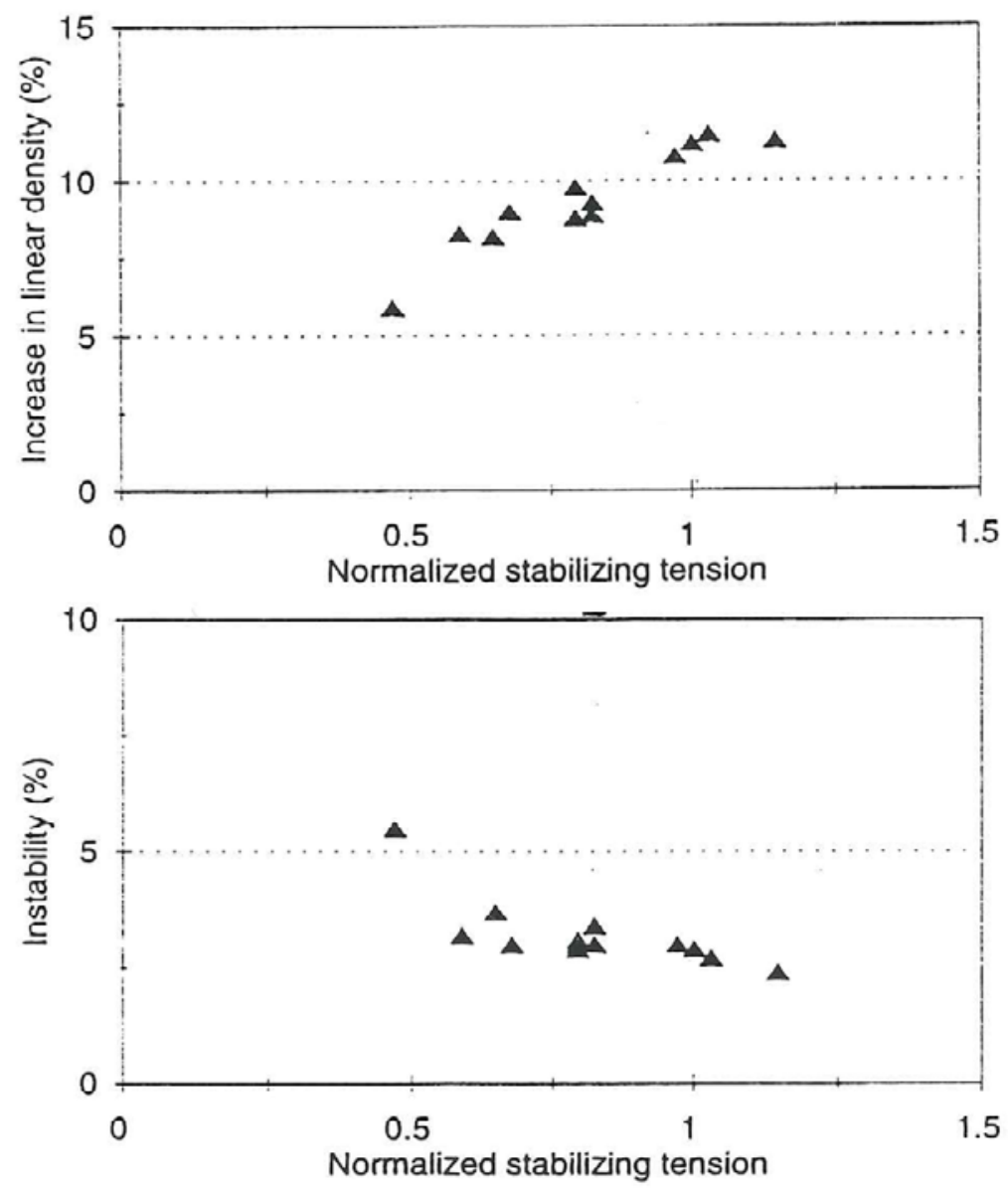

FIGURE 7. Correlation between (a) normalized stabilizing tension and linear density increase for all rectangular nozzles tested, and (b) normalized stabilizing tension and yam instability for all rectangular nozzles tested. 


\section{EFFECTS OF GEOMETRIC PARAMETERS}

The test results provide insight into the effect of geo- metric parameters on the outcome of the texturing process. Nozzle geometries 1 and 12 produce unstable processes.

Nozzle 1 has an air inlet hole positioned very close to the curved nozzle exit. The jet emerges from the air inlet at an angle of $45^{\circ}$ to the yarn path and the nozzle is configured such that the jet leaves without impacting on the main channel cross section. The resulting yarn path in the vicinity of the nozzle exit is thus directed at $45^{\circ}$ from the main channel direction. The absence of a curved diverging exit profile in nozzle 12 also leads to major changes in the exit yarn path during texturing, which give rise to unfavorable air/yam interaction and an unstable process as well.

Nozzles 2 and 3 yield poorly textured yarns, and changes to the primary flow length between 4 and $7 \mathrm{~mm}$ give rise to erratic behavior of the texturing parameters. These effects are attributable to a poor air flow path and, consequently, a poor yarn path in all these cases. The short distance between air inlet and the exit of nozzles 2 and 3 causes jet impingement on the main flow channel without subsequent flow redevelopment in the axial direction before exiting from the nozzle. Miller [7] and Ward-Smith [9] state that after abrupt area changes of modest area ratio, a distance of at least two to four equivalent duct diameters $D e$ (for rectangular passages, this parameter is given by $2 h w /(h+w)$ is required as a minimum for flow redistribution. Hence, there will still be major velocity profile distortions in the exit flows of nozzles 2 and 3. In the case of nozzle 2, it appears that an intermediate texturing regime establishes itself with a distorted air flow distribution, a largely correct yarn path, and sufficient secondary flow and turbulence to give texturing.

Further increase of the primary flow length above $7 \mathrm{~mm}$ allows the flow to redevelop progressively more in the axial direction. This has beneficial effects on the texturing quality. The best texturing, indicated by the highest stabilizing tension and largest increase in linear density, therefore occurs with the longest primary flow lengths.

The results for different air inlet angles lead to some- what contradictory conclusions. The texturing quality, as indicated by tension in the stabilizing zone and the SEM images, seems highest for the $45^{\circ}$ inlet followed by the $30^{\circ}$ inlet and lowest for the nozzle with a $60^{\circ}$ inlet. However, the increase in linear density was highest for the $30^{\circ}$ inlet, and the instability was lowest for this nozzle. A low inlet angle is therefore beneficial, but further research is needed to establish the optimum angle.

Nozzle 13 with two air inlets yields yarns with some- what poorer texturing quality than nozzle 5, and the two inlets very substantially increase air consumption. So for these rectangular nozzles, two inlets are not worthwhile.

Although the SEM images suggest that the loops of the yarn produced by nozzle 14 (diverging main channel) are not as small as those for T100, this nozzle gives yarns with the best objective measurements of texturing:-high tension in the stabilizing zone, high increase in linear density, and low instability. The divergence in the main channel is therefore clearly beneficial.

Work by Acar et al. [4] has suggested that a certain degree of non-uniformity of the primary flow velocity distribution may play a role in defining favorable texturing conditions. Our work on rectangular nozzles shows that there are benefits associated with the improved axial flow orientation and more uniform, symmetrical 
velocity distributions associated with longer nozzles and with shallow air inlet angles. Most of the experimental nozzles tested with rectangular cross sections were capable of producing textured yarns with qualities comparable to those obtained from industrial nozzles. Rectangular cross-sectional nozzles have proved to be at least as effective as cylindrical nozzles and much easier to manufacture:-This would give the rectangular nozzles the potential for commercial exploitation.

\section{Literature Cited}

1. Acar, M., Burton, R. K., and Wray, G. R., An Analysis of the Air-Jet Yarn Texturing Process, Part II: An Experimental Investigation of the Air Flow, J. Textile Inst. 77 ( 1), 28-43 (1986).

2. Acar, M., Burton, R. K., Wray, G. R., An Analysis of the Air-Jet Yam Texturing Process, Part III: Filament Behaviour during Texturing, J. Textile Inst. 77 (4), 235- 246 (1986).

3. Acar, M., Turton, R. K., and Wray, G. R., An Analysis of the Air-Jet Yam Texturing Process, Part IV: Fluid Forces Acting on the Filaments and the Effects of Filament Cross-Section Area and Shape, J. Textile Inst. 77 (4), 247-254 (1986).

4. Acar, M., Turton, R. K., and Wray, G. R., Air Flow in Yam Texturing Nozzles, Trans. ASM E J. Eng. Ind.109 (3), 197-202 ( 1987).

5. Demir, A., Acar, M., and Turton, R. K., Air Flow in Nozzles, Textile Asia 11 (8), 7780, 89-93 (1990).

6. Demir, A,Acar, M., and Wray, G. R., Instability Tests for Air-jet Textured Yarns, Textile Res. J.56 (3), 191- 202 (1986).

7. Miller, D.S., "Internal Flow Systems," British Hydro-mechanics Research Association, Cranfield, Bedford, UK, 1978.

8. Versteeg, H. K., Bilgin, S., and Acar, M., Effects of Geometry on the Flow Characteristics and Texturing Performance of Air-Jet Texturing Nozzles, Textile Res. J. 64 (4) , 240-246 (1994).

9. Ward-Smith, A. J., "Internal Flow," Clarendon Press, Oxford, UK, 1980.

10. Wray, G. R., and Acar, M., Supersonic Jet Texturing of Yarns, Proc. IMechE Part BJ. Eng. Manuf. 204, 71-89 (1990). 